of menopause-associated vasomotor symptoms: position statement of the North American Menopause Society. Menopause 2004;11(1):11-33.

Competing interests: None declared.

DOI:10.1503/cmaj.1050024

We received no response from Dr. Mclntyre and colleagues to our invitation to reply to these letters.

\section{Standards for pharmaceutical advertising in Canada}

$\mathrm{R}$ ichelle Cooper and David Schriger ${ }^{1}$ report their analysis of original research cited in pharmaceutical advertisements appearing in medical journals published in the United States. However, the standards for advertisements in US medical journals differ from those for Canadian ones. Almost all of the advertisements appearing in the latter are reviewed and precleared by the Pharmaceutical Advertising Advisory Board (PAAB). The standards of the PAAB "Code of Advertising Acceptance" are publicly available. ${ }^{2}$

Advertising reviewed and authorized by the PAAB must meet the following criteria:

- The advertisement must contain a list of references for medical claims. These references are analyzed by PAAB reviewers, who have received training in critical appraisal from expert academics teaching at leading Canadian medical schools.

- All references used to support claims must be provided to the PAAB during the review process, which provides assurance that they exist and are obtainable.

- All references used must be available to health care professionals on request.

- The advertisement must not contain data-on-file references unless such studies were part of a New Drug Submission reviewed by Health Canada.

Although not prohibited by the PAAB code, the fact that the majority of original research cited to substantiate claims is in some way affiliated with the product's manufacturer is considered during the review process. The code re- quires that "Clinical/therapeutic claims must be based on published, wellcontrolled and/or well-designed studies with clinical and statistical significance clearly indicated. Publication in peerreviewed journals is usually a good criterion for establishing scientific rigor."” This exceeds the standard for accredited continuing education events.

Ray Chepesiuk

Commissioner

Pharmaceutical Advertising Advisory

Board

Pickering, Ont.

\section{References}

1. Cooper RJ, Schriger DL. The availability of references and the sponsorship of original research cited in pharmaceutical advertisements. CMA7 2005;172(4):487-91.

2. Code of advertising acceptance. Pickering $(\mathrm{ON})$ : Pharmaceutical Advertising Advisory Board; 2005. Available: www.paab.ca/index_en.html (accessed 2005 Apr 26).

DOI:10.1503/cmaj.1050056

\section{[The authors respond:]}

W e thank Ray Chepesiuk for identifying important differences between Canada and the United States in the regulation of pharmaceutical advertisements and applaud the Canadian effort. Canadian regulations with regard to prerelease review of advertisements are unquestionably more stringent. We are concerned, however, that in neither country is the regulatory effort adequate to ensure that all of the relevant information is available to those making decisions about the effectiveness and costeffectiveness of medications. ${ }^{1}$ Although the pharmaceutical industry's recent commitment $^{2}$ to make all clinically relevant trial data available on an industrysponsored Web site (www.clinical studyresults.org) may help in this regard, at present much relevant material remains unpublished, and peer-reviewed publications often fail to tell the whole story. ${ }^{3}$ Trial registry with electronic publication of research protocols before inception of each trial ${ }^{4,5}$ and Web posting of complete data sets upon publication of the findings are 2 measures that could promote greater comprehensiveness and honesty in the reporting of trials.
Even if these measures are enacted, clinicians should remember that advertising exists to create a demand for a product and that claims made in advertisements may or may not be true. It is therefore imperative that all relevant information is on the table before clinicians and patients make decisions about the utility of medications. Despite increasing regulation, more remains to be done, and "caveat emptor" still applies.

\section{Richelle J. Cooper \\ David L. Schriger \\ UCLA Emergency Center \\ UCLA School of Medicine \\ Los Angeles, Calif.}

\section{References}

1. Cooper RJ, Schriger DL. The availability of references and the sponsorship of original research cited in pharmaceutical advertisements. CMAf 2005;172(4):487-91.

2. New database provides doctors and patients unprecedented access to clinical study information for marketed medicines [press release]. Washington: Pharmaceutical Research and Manufacturers Association; 2004 Sept 7. Available: www.phrma .org/mediaroom/press/releases/07.09.2004.1063 cfm (accessed 2005 May 18).

3. Smith R. Medical journals are an extension of the marketing arm of pharmaceutical companies. PLoS Med 2005;2(5):e138.

4. De Angelis C, Drazen JM, Frizelle FA, Haug C, Hoey J, Horton R, et al; International Committee of Medical Journal Editors. Clinical trial registration: a statement from the International Committee of Medical Journal Editors. CMAJ 2004;171(6):606-7.

5. De Angelis CD, Drazen JM, Frizelle FA, Haug $\mathrm{C}$, Hoey J, Horton R, et al. Is this clinical trial fully registered? A statement from the International Committee of Medical Journal Editors. CMA7 2005;172(13):1700-2.

Competing interests: None declared.

DOI:10.1503/cmaj.1050124

\section{Time-dependent analysis in CHF follow-up}

Tustin Ezekowitz and colleagues ${ }^{1}$ have concluded that patients with congestive heart failure who are followed by specialists and family physicians (FPs) experience better survival than patients who are followed by FPs alone; however, their analysis is not internally consistent.

In the Methods section they state, quite appropriately, that "[a] time-dependent analysis is essential when examining the effect of physician follow-up because patients' outcomes can determine their 